\title{
TEMPORAL CHARACTERISTICS OF AEROSOL PHYSICAL PROPERTIES AT VISAKHAPATNAM ON THE EAST COAST OF INDIA
}

\author{
Siriki Srinivasa Rao* \\ Physics Mrs.A.V.N. College, Visakhapatnam Andhra Pradesh, India \\ DOI: http://dx.doi.org/10.24327/ijrsr.2017.0805.0235
}

\section{ARTICLE INFO}

\section{Article History:}

Received $17^{\text {th }}$ February, 2017

Received in revised form $21^{\text {th }}$

March, 2017

Accepted $28^{\text {th }}$ April, 2017

Published online $28^{\text {th }}$ May, 2017

\section{Key Words:}

Aerosols, Radiative forcing, Aerosol optical depth.

\begin{abstract}
An extensive, multi institutional, multi instrumental and multi-platform field experiment 'Integrated Campaign Aerosols, gases and Radiation Budget (ICARB) was carried out. The objective this Campaign ever conducted in the Indian region was to characterize the physico-chemical properties and radiative effects of the aerosols and trace gases over the Indian landmass and the adjoining oceanic regions of the Arabian Sea, Northern Indian Ocean, and Bay of Bengal. The temporal variations of aerosol optical depth, near surface aerosol mass size distributions and BC mass concentrations show significantly higher aerosol optical depth and near surface mass concentrations during the first and last weeks of April 2007. The mean BC mass fraction in the fine mode aerosol was around of $11 \%$. A comparison of the temporal variation of the Aerosol properties at Visakhapatnam with the MODIS derived aerosol optical depth along the cruise locations indicate a significant coincidence suggesting that the aerosol transport from the eastern coastal regions of the peninsular India plays an important role on the observed spatial variation in the aerosol optical depths over the near coastal oceanic regions of Bay of Bengal.
\end{abstract}

Copyright (C) Siriki Srinivasa Rao, 2017, this is an open-access article distributed under the terms of the Creative Commons Attribution License, which permits unrestricted use, distribution and reproduction in any medium, provided the original work is properly cited.

\section{INTRODUCTION}

The Earth's climate system constantly adjusts so as to maintain a balance between the energy that reaches it from the sun and the energy that goes from Earth back to space. Aerosols are the particles of matter or liquid that can be produced by natural or man-made activities. Though these particles constitute only a very small fraction of the atmospheric species $(0.00005 \%$ by volume), their effects are quite significant. The interactions of aerosols with the radiation passing through atmosphere also produce significant spectral deformation in the satellite imageries. Therefore characterization of optical and physical properties of atmospheric aerosols is of prime importance in global change studies.

During November to May, the mean wind flow favours the transport of aerosol from central and eastern India which can influence the radiation budget over northern Bay of Bengal. Aerosol Black Carbon (the absorbing aerosol) is an important constituent that needs to be characterized in evaluating the net aerosol radiative forcing. $\mathrm{BC}$ has relatively longer residence time and hence can get transported downwind over long distances, even to the remote oceanic regions. Moorthy and Babu (2006) reported that when the airmass trajectories arrive at Port Blair (an island location of India in BOB) either from India or the east Asia, the $\mathrm{BC}$ concentrations are high and are insensitive to the region from where they are arriving indicating the importance of long range $\mathrm{BC}$ transport with potential impact over the oceanic regions in their transit. Such transport of aerosols from the source regions on the continent to remote oceans could play a significant role in the global radiative forcing. The primary objectives of field campaigns over the oceanic regions could be to understand the extent to which the continental aerosols, both natural and anthropogenic can be transported over the clean oceanic regions and to characterize the meteorological processes that are responsible for such transport, since neither the quantities of emissions nor the global distribution of aerosols, particularly in the tropics and sub-tropics are even approximately known until recently.

\section{DATA AND METHODOLOGY}

Visakhapatnam $\left(17.7^{\circ} \mathrm{N}, 83.3^{\circ} \mathrm{E}\right)$ is a coastal industrial location on the east coast of India. During the ICARB period, the Aerosol spectral Optical Depths (AOD) were measured using a Microtops II sun Photometer operating at 380, 440, 500, 675 and $870 \mathrm{~nm}$. Size segregated near surface aerosol mass concentrations were measured using a Quartz Crystal Microbalance (California Measurements Inc., USA) in 10 size channels with $50 \%$ aerodynamic cut-off diameters at $25,12.5$, $6.4,3.2,1.6,0.8,0.4,0.2,0.1$ and $0.05 \mu \mathrm{m}$ respectively with an air inlet at a flow rate of 0.24 liters per minute and sampled for 
duration of 300 seconds for each measurement. A seven channel Magee Scientific Aethalometer was used to measure the near surface BC mass concentration. Niranjan et al., 2006, 2007 and Sreekanth et al., 2007.

\section{RESULTS AND DISCUSSION}

\section{Aerosol Optical Depth}

Aerosol optical depth is one single parameter that can characterize the atmospheric transparency. In figure 1 are shown the temporal variation of the Aerosol optical depth at $500 \mathrm{~nm}$ measured using a Microtops II sun Photometer at Visakhapatnam. The vertical line indicates the period when the ship was sailing in Bay of Bengal. The AOD shows a distinct day to day variability during the campaign period at Visakhapatnam. Significantly large Optical depths above the mean values (black line shown at 0.55 AOD) were observed during the first and last weeks of April 2006 with AOD at 500 $\mathrm{nm}$ crossing 0.7. An examination of the MODIS data for this station for the said period indicates a one to one correspondence between the ground based measurements (Microtops) and the MODIS data, with the Microtops optical depths. that the near surface mass concentration also shows large day to day variability with relatively high values during the first half of April 2006. There was a slight increasing tendency during the last week of April.

To see the relative change in the aerosol mass size distribution, we have sorted the size segregated data in to nucleation (aerodynamic mean radius $<0.1 \mu \mathrm{m}$ ), accumulation (aerodynamic mean radius between $0.1 \mu \mathrm{m}$ to $1.0 \mu \mathrm{m}$ ) and coarse modes (aerodynamic mean radius $>1.0 \mu \mathrm{m}$ ) and their day to day variability are shown in figure 3 . The accumulation mode aerosol shows higher mass concentration and comparable day to day variability similar to total mass concentration during the first week of April 2006 while during the last week of April no significant increase in the surface accumulation mode mass is observed. On the contrary the nucleation mode aerosol shows some increase in the last week of April 2006. This indicates decoupling of column integrated features as seen in AOD from the near surface features as seen from the QCM mass distributions. To bring out the decoupling features more clearly, we have plotted the variation of the Angstrom aerosol size index alpha as a function of surface nucleation and accumulation mode aerosol mass concentration

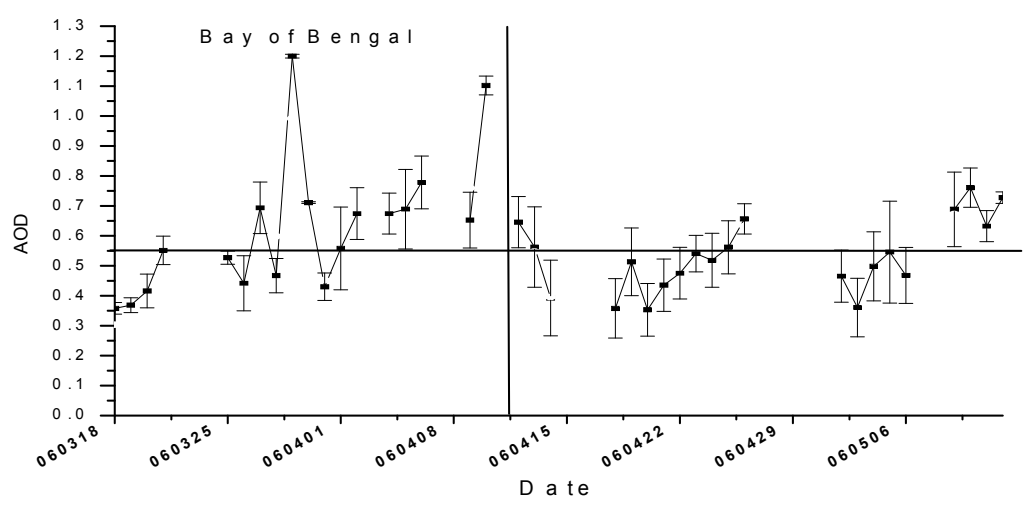

Figure 1 Temporal variation of Microtops AOD $(0.5 \mu \mathrm{m})$. Horizontal line indicates mean values. The vertical line indicates the BOB leg.

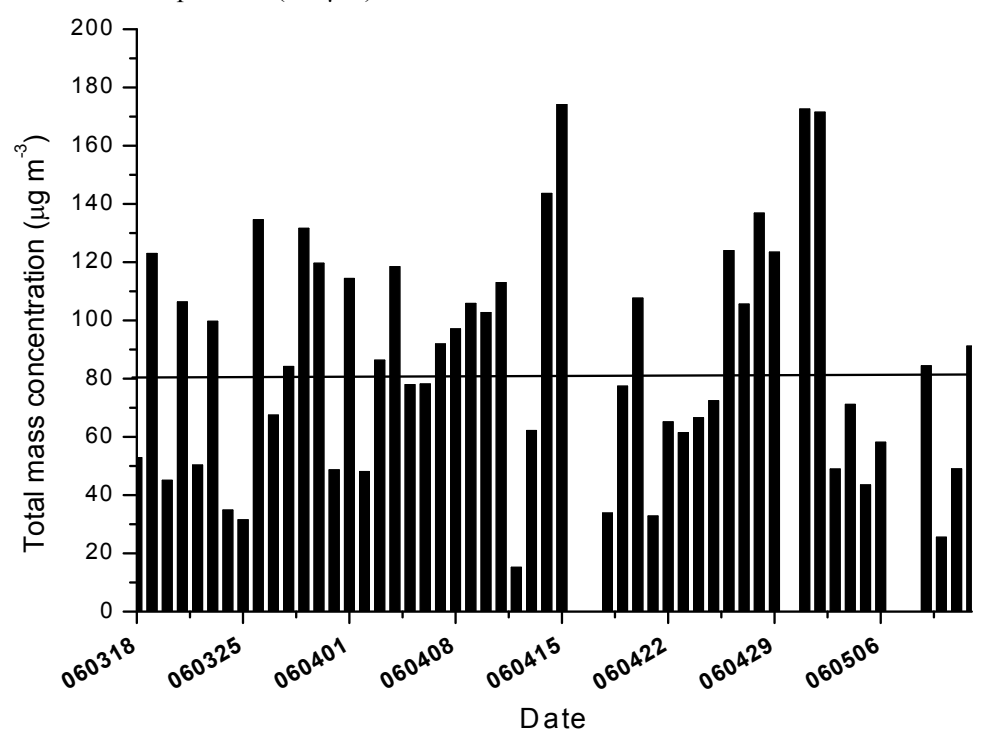

Figure 2 Temporal variation of near surface total mass concentration.

\section{Near Surface aerosol mass concentration and BC mass Concentrations}

In figure 2 are shown the near surface aerosol total mass concentrations measured by the QCM system. It may be seen measured by QCM in figures 4 and 5 respectively. Assuming that the aerosol size distribution is uniform in the column integrated properties, an increase in alpha should be associated with a proportionate increase in the surface fine mode mass. 

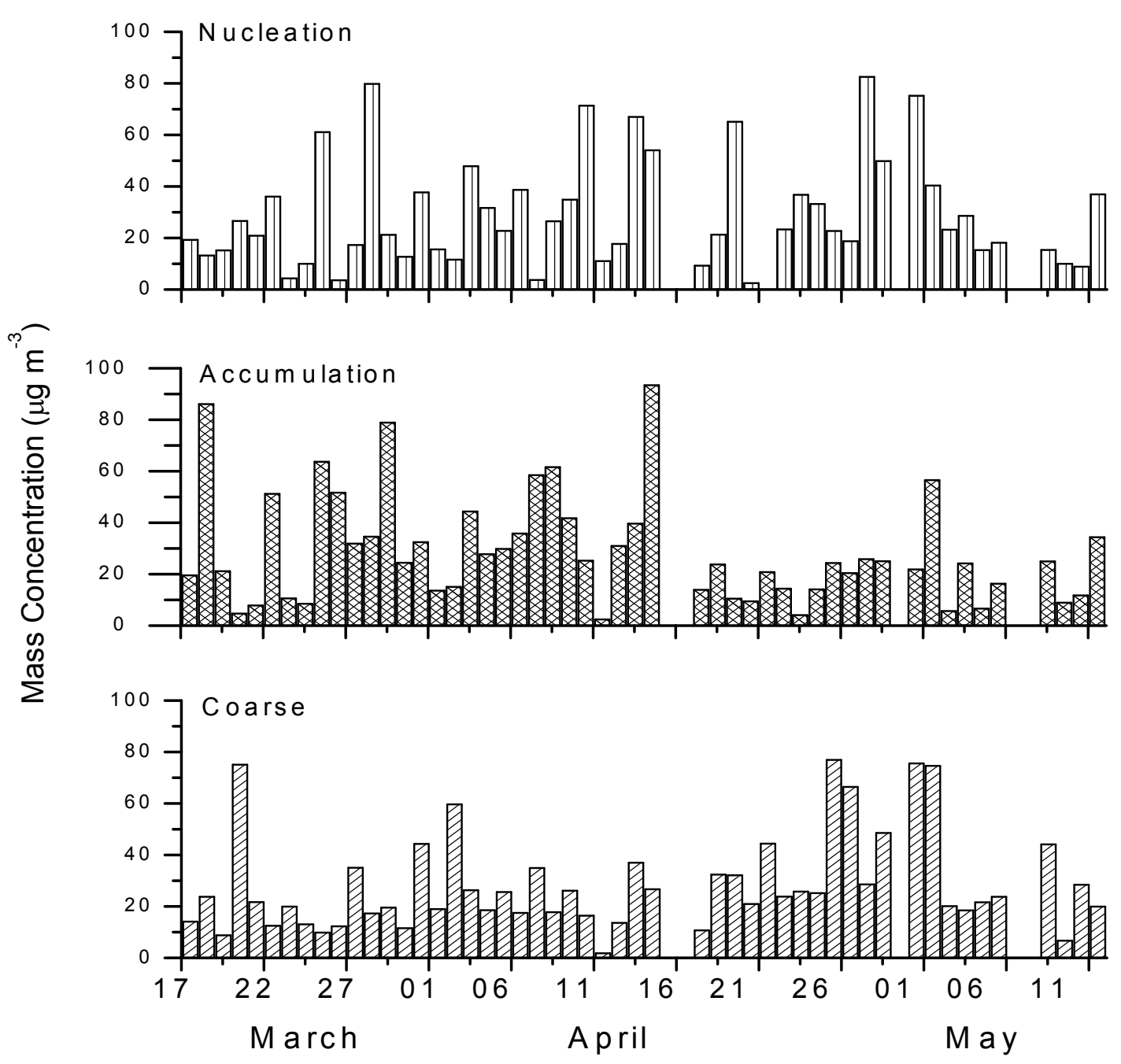

Figure 3 Temporal variation of size segregated mass concentration in the nucleation, accumulation and coarse mode

The solid line in both the plots indicates the regression line which supports this assumption. But in some cases shown as solid dots in these figures, an increase in alpha is not associated with a proportionate increase in surface fine mode aerosol mass (either in the nucleation or accumulation mode) indicating that the surface aerosol features differ from the column integrated aerosol physical properties. This indicates the need for vertical profiling of aerosol mass concentration as the difference observed in the near surface and column integrated feature could be due to the changes in the aerosol physical properties at altitudes above the mixing region

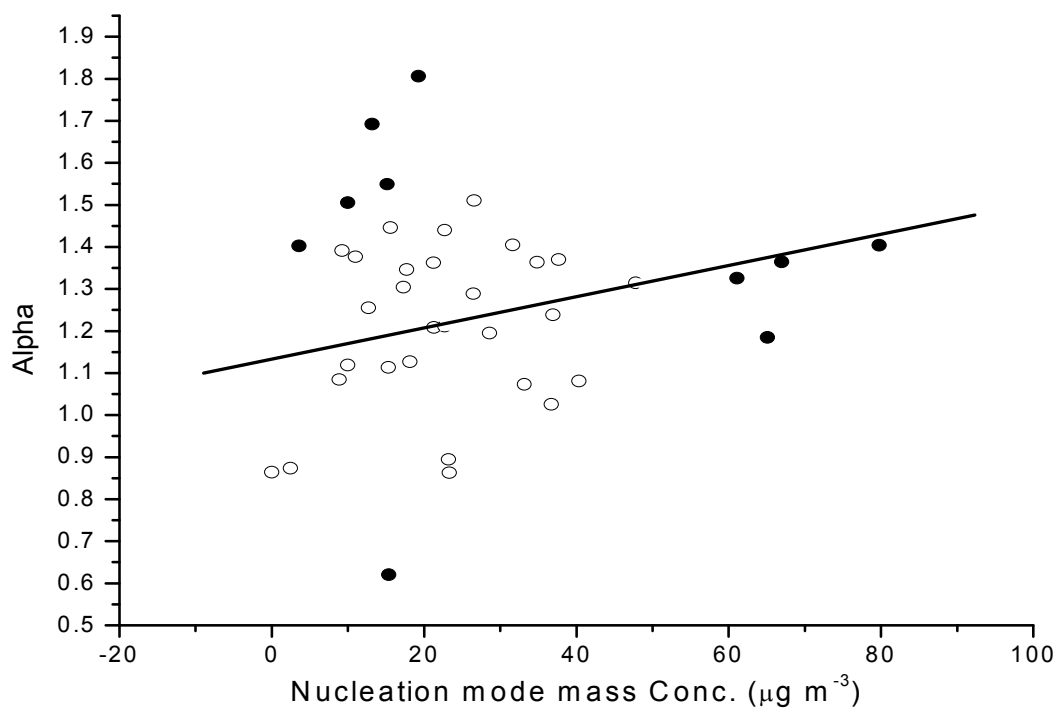

Figure 4 Plot showing the variation of aerosol size index as a function of near surface nucleation mode aerosol mass concentration. 
In figure 6 are shown the surface $\mathrm{BC}$ mass concentrations at $1000 \mathrm{hrs}$ and $1500 \mathrm{hrs}$ IST for all the days of observations during the campaign period. It may be seen that the surface BC mass concentrations were higher during the first and last weeks of April 2006 as seen in the surface aerosol mass concentrations and the aerosol optical depths. largely depending on the continental sources. In this context the measurements at adjoining coastal locations like Visakhapatnam during ICARB assume importance, particularly with reference to the cruise observations in the Bay of Bengal region.

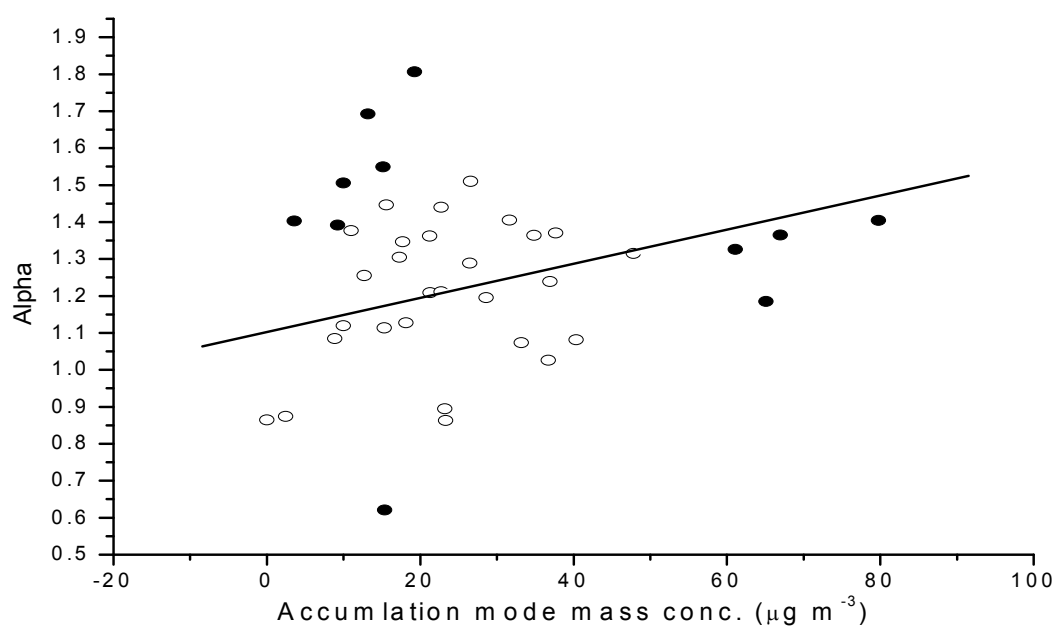

Figure 5 Plot showing the variation of aerosol size index as a function of near surface accumulation mode aerosol mass concentration.

However, very large values of $\mathrm{BC}$ mass concentration were recorded during 19-24 ${ }^{\text {th }}$ March 2006. The percent BC mass fraction in the fine mode aerosol was 11 though on some days in fluctuated significantly from this mean value. A more detailed discussion on the $\mathrm{BC}$ mass fraction to the composite aerosol at Visakhapatnam, its relation to column AODs and the implications on BC radiaitive forcing are available in Sreekanth et al., (2007).
Meteorological studies show that the high aerosol concentrations over the Arabian Sea and tropical Indian Ocean could be linked to transport from Indian sub-continent and also from sources in the Middle East and North Africa (Krishnamurti et al., 1998).

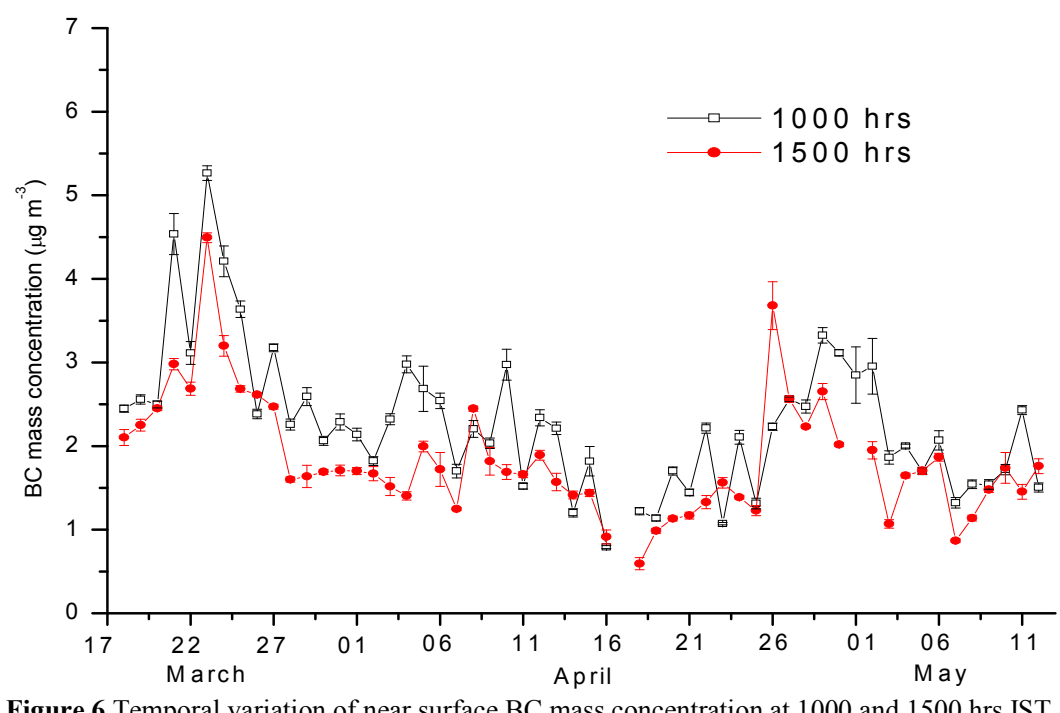

\section{DISCUSSION}

Systematic characterization of aerosols over the oceans is needed to understand the aerosol effect on climate and on transport of pollutants between continents (Smirnov et al., 2002). Villevalde et al. (1994) reported that the optical properties of maritime aerosols influencing the Pacific Ocean measurements are substantially different from those of the north Atlantic data indicating the regional differences in the aerosol properties of oceanic regions. It was reported that in coastal areas and inland seas the values of AOD are higher
In order to see if the observed temporal variation in the aerosol physical properties are in anyway affecting the spatio-tempral variations in the aerosol optical depth along the cruise track, we have compared the MODIS aerosol optical depth at $550 \mathrm{~nm}$ along the cruise track in the Bay of Bengal region with the temporal variation in the aerosol optical depth at Visakhapatnam and are shown in figure 7 The aerosol optical depths along the cruise track were in general low compared to the AODs observed at Visakhapatnam. 


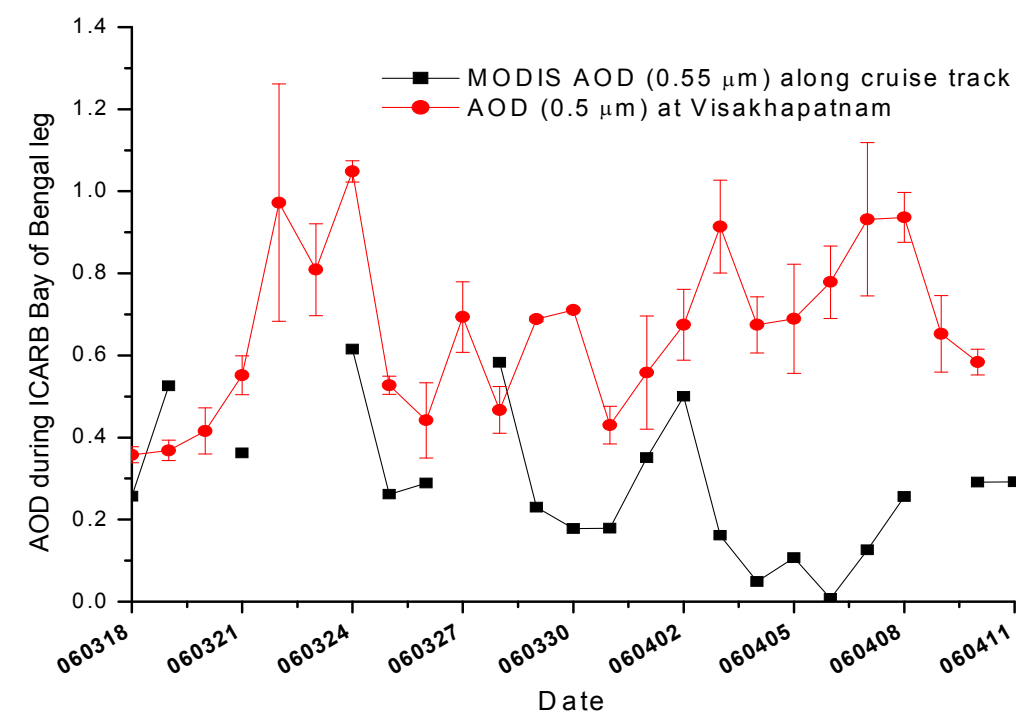

Figure 7 Temporal variation of MODIS AOD $(0.55 \mu \mathrm{m})$ along the ICARB Bay of Bengal cruise track and Microtops AOD $(0.5 \mu \mathrm{m})$ at Visakhapatnam

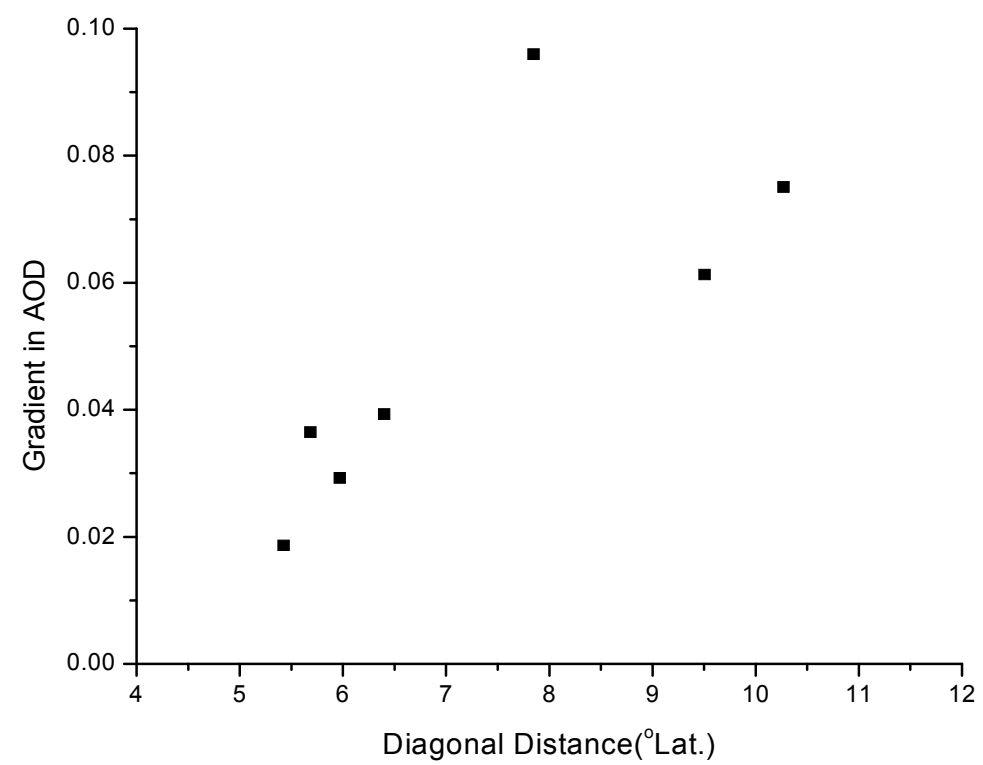

Figure 8 Gradients in aerosol optical depth (per Deg latitude diagonal distance from Visakhapatnam to the different cruise locations.

But it is interesting to see the temporal variation at Visakhapatnam is getting reflected as a spatial variability with a good resemblance. Satheesh and Moorthy 1997 reported significant enhancement in AOD at shorter wavelengths in the near coastal regions compared to far coastal regions and that the Ängstrom exponent ' $\alpha$ ' doubles in the near coastal regions compared to far coastal regions. Airmasses that come from different source regions into the Bay of Bengal region carrying aerosols of different species are responsible for the spatial and temporal variations in the observed AOD spectra (Ramachandran and Jayaraman 2003). Major sources of aerosols over the northern Bay of Bengal are the eastern coast of India (Ganguly et al., 2005 and Satheesh et al., 2006). Vinoj et al (2004) also reported that aerosol optical depths over BOB were high with $\alpha$ approximately equal to 1.1 indicating the presence of significant amount of sub-micron aerosol. It is known from the general wind pattern that the air mass pathways are from peninsular India on to the Northern BOB and it is quite possible that the mean wind flow from the peninsular India via the eastern coastal regions could significantly contribute to the aerosol loading over the regions covered by the ICARB track. The observed results from the eastern coastal region of Visakhapatnam in conjunction with the MODIS derived AODs over the cruise track are in conformity with this proposition. To get an idea on the scaling distance of continental influence on the aerosol properties over the oceanic regions, we have evaluated the gradient in AOD (along the diagonal path) at various cruise locations, assuming Visakhapatnam as the source point for the outflow from the continental region and the results are presented in figure 8 It may be seen that in the near coastal locations, the AOD gradient is low (approximately 0.03 per deg latitude), while in the farther coastal regions the gradient is high. This indicates that the near coastal regions are significantly affected by the aerosol sources from the nearby continental locations while the influence falls off rapidly as the distance from the coast increases.

\section{Acknowledgements}

I express my deepest sense of gratitude and sincere thanks to my research supervisor Prof. K. Niranjan, Andhra University, 
Visakhapatnam for his able guidance, constant encouragement and help in my research work.

\section{References}

1. Ganguly, D., A. Jayaraman, and H. Gadhavi (2005), In situ ship cruise measurements of mass concentration and size distribution of aerosols over Bay of Bengal and their radiative impacts, J. Geophys. Res., 110, D06205, doi: 10.1029/2004JD005325.

2. Krishnamurti, T. N., B. Jha., J. Prospero, A. Jayaraman, and V. Ramanathan, (1998), Aerosol and pollutant transport and their impact on radiative forcing over the tropical Indian Ocean during the January-February 1996 pre-INDOEX cruise, Tellus, 50B, 521-542.

3. Moorthy, K. K., and S. S. Babu (2006), Aerosol black carbon over Bay of Bengal observed from an island location, Port Blair: Temporal features and long-range transport, J. Geophys. Res., 111, D17205, doi:10.10 29/2005JD006855.

4. Moorthy, K.K., S.K. Satheesh, S. Suresh Babu and C B S Dutt (2008), Integrated campaign for aerosols, gases and Radiation Budget : An overview, J. of Earth systems science, 117, 243-262

5. Niranjan, K., V. Sreekanth, B. L. Madhavan, and K. Krishna Moorthy (2006), Wintertime aerosol characteristics at a north Indian site Kharagpur in the Indo-Gangetic plains located at the outflow region into Bay of Bengal, J. Geophys. Res., 111, D24209, doi: 10.1029/2006JD007635.

6. Niranjan, K., B. L. Madhavan, and V. Sreekanth (2007), Micro pulse lidar observation of high altitude aerosol layers at Visakhapatnam located on the east coast of India, Geophys. Res. Lett., 34, L03815, doi: 10.1029/2006GL028199.
7. Parameswaran, K., K. Rajeev, and K. Sen Gupta (1997), An observational study of night time aerosol concentrations in the lower atmosphere at a tropical coastal station, J. Atmos. Sol. Terr. Phys., 59(14), 17271737.

8. Ramachandran, S, and A. Jayaraman (2003), Spectral aerosol optical depths over Bay of Bengal and Chennai: I-measurements, Atmospheric Environment, 37, 19411949.

9. Satheesh, S. K, and K. Krishna Moorthy, (1997), Aerosol characteristics over coastal regions of the Arabian Sea, Tellus, 49B, 417-428.

10. Satheesh, S. K., J. Srinivasan, and K. K. Moorthy (2006), Spatial and temporal heterogeneity in aerosol properties and radiative forcing over Bay of Bengal: Sources and role of aerosol transport, J. Geophys. Res., 111, D08202, doi:10.1029/2005JD006374.

11. Smirnov, A., B. N. Holben, Y. J. Kaufman, O. Dubovik, T. F. Eck., I. Slutsker, C.Pietras, and R. N. Halthore, (2002), Optical properties of atmospheric aerosol in maritime environments, J. Atmos. Sci., 59, 501-523.

12. Sreekanth, V., K. Niranjan, and B. L. Madhavan (2007), Radiative forcing of black carbon over eastern India, Geophys. Res. Lett., 34, L17818, doi: 10.1029/2007 GL030377.

13. Villevalde, Y. V., A. V. Smirnov., N. T. O’Neill., S. P. Smyshlyaev, and V. V. Yakovlev, (1994), Measurement of aerosol optical depth in the Pacific Ocean and the North Atlantic, J. Geophys. Res., 99, D10, 20,98320,988 .

14. Vinoj, V., S. S. Babu, S. K. Satheesh, K. K. Moorthy, and Y. J. Kaufman (2004), Radiative forcing by aerosols over the Bay of Bengal region derived from shipborne, island-based, and satellite (Moderate-Resolution Imaging Spectroradiometer) observations, J. Geophys. Res., 109, D05203, doi: 10.1029/2003JD004329.

\section{How to cite this article:}

Siriki Srinivasa Rao.2017, Temporal Characteristics of Aerosol Physical Properties at Visakhapatnam on the East Coast of India. Int J Recent Sci Res. 8(5), pp. 16876-16881. DOI: http://dx.doi.org/10.24327/ijrsr.2017.0805.0235 